\title{
Activity-Dependent Presynaptic Regulation of Quantal Size at the Mammalian Neuromuscular Junction In Vivo
}

\author{
Xueyong Wang, ${ }^{1}$ Yingjie Li, ${ }^{1}$ Kathrin L. Engisch, ${ }^{2}$ Stan T. Nakanishi, ${ }^{2}$ Sara E. Dodson, ${ }^{1}$ Gary W. Miller, ${ }^{1}$ \\ Timothy C. Cope, ${ }^{2}$ Martin J. Pinter, ${ }^{2}$ and Mark M. Rich ${ }^{1,2}$ \\ ${ }^{1}$ Center for Neurodegenerative Disease and ${ }^{2}$ Department of Physiology, Emory University School of Medicine, Atlanta, Georgia 30322
}

\begin{abstract}
Changes in synaptic activity alter quantal size, but the relative roles of presynaptic and postsynaptic cells in these changes are only beginning to be understood. We examined the mechanism underlying increased quantal size after block of synaptic activity at the mammalian neuromuscular junction in vivo. We found that changes in neither acetylcholinesterase activity nor acetylcholine receptor density could account for the increase. By elimination, it appears likely that the site of increased quantal size after chronic block of activity is presynaptic and involves increased release of acetylcholine. We used mice with muscle hyperexcitability caused by mutation of the ClC-1 muscle chloride channel to examine the role of postsynaptic activity in controlling quantal size. Surprisingly, quantal size was increased in $\mathrm{ClC}$ mice before block of synaptic activity. We examined the mechanism underlying increased quantal size in $\mathrm{ClC}$ mice and found that it also appeared to be located presynaptically. When presynaptic activity was completely blocked in both control and $\mathrm{ClC} \mathrm{mice,}$ quantal size was large in both groups despite the higher level of postsynaptic activity in $\mathrm{ClC}$ mice. This suggests that postsynaptic activity does not regulate quantal size at the neuromuscular junction. We propose that presynaptic activity modulates quantal size at the neuromuscular junction by modulating the amount of acetylcholine released from vesicles.
\end{abstract}

Key words: transmitter release; synaptic plasticity; neuromuscular junction; synaptic activity; quantal size; homeostatic

\section{Introduction}

The amplitude of spontaneously occurring miniature currents is determined by the response of a postsynaptic cell to the transmitter contained in a single vesicle. This amplitude, quantal size, is of importance in determining synaptic strength, and its modulation provides one way of controlling postsynaptic activity. Evidence that activity plays an important role in modulating quantal size comes from experiments in which increasing synaptic activity reduced quantal size, whereas decreasing synaptic activity increased quantal size (O'Brien et al., 1998; Turrigiano et al., 1998; Burrone et al., 2002; Desai et al., 2002). A current expression of this idea is the homeostatic theory of synaptic plasticity in which synaptic strength (amplitude of the synaptic current) increases when activity decreases and decreases when activity has been upregulated (Davis and Bezprozvanny, 2001; Burrone and Murthy, 2003; Turrigiano and Nelson, 2004).

An increase in quantal size can occur because of either a presynaptic mechanism (increased release of neurotransmitter) or a postsynaptic mechanism (increase in the number of postsynaptic receptors). It has been proposed that the postsynaptic cell is the primary site of expression of homeostatic changes in quantal size (Turrigiano and Nelson, 2004). This proposal is based on exper-

Received Sept. 22, 2003; revised 0ct. 29, 2004; accepted Nov. 13, 2004

This work was supported by National Institutes of Health Grant P01 NS 40405 (M.M.R.). We thank Peter Wenner for helpful comments.

Correspondence should be addressed to Mark Rich, Neurodegenerative Disease Center, Emory University School of Medicine, 615 Michael Street, Atlanta, GA 30322. E-mail: mmrich@emory.edu. DOI:10.1523/JNEUROSCI.3252-04.2005

Copyright $\odot 2005$ Society for Neuroscience $\quad$ 0270-6474/05/250343-09\$15.00/0 iments in which neurotransmitter receptor number, estimated by response to application of neurotransmitter and by quantitative immunofluorescence, was found to be increased after treatments that increased quantal size (O’Brien et al., 1998; Turrigiano et al., 1998; Watt et al., 2000).

The mammalian neuromuscular junction (NMJ) is a classic synaptic preparation that is ideally suited to studies of synaptic function in vivo, because there is only one presynaptic input and one neurotransmitter. Blockade of neuromuscular activity normally triggers an increase in postsynaptic expression of acetylcholine receptors (AChRs) (Lomo and Rosenthal, 1972; Lomo and Westgaard, 1975). It is unknown whether this increase in AChRs causes an increase in quantal size. We found that quantal size increased at the NMJ after block of synaptic activity. We examined both the mechanism and trigger underlying increased quantal size after block of synaptic activity. To determine the mechanism underlying increased quantal size, we examined whether reduced acetylcholinesterase (AChE) activity or increased acetylcholine receptor density could account for the increase in quantal size. To identify the trigger for increased quantal size, we blocked nerve activity in both control mice and mice in which muscle is spontaneously active because of a mutation in the muscle-specific ClC-1 chloride channel (Klocke et al., 1994). These mice make it possible, for the first time, to selectively block presynaptic activity, a manipulation previously impossible at the neuromuscular junction.

\section{Materials and Methods}

Solutions and measurement of resting potential. In all experiments the recording chamber was perfused continuously with Ringer's solution 
containing (in mm/l): $118 \mathrm{NaCl}, 3.5 \mathrm{KCl}, 2 \mathrm{CaCl}_{2}, 0.7 \mathrm{MgSO}_{4}, 26.2$ $\mathrm{NaHCO}_{3}, 1.7 \mathrm{NaH}_{2} \mathrm{PO}_{4}, 5.5$ glucose, pH 7.3-7.4 $\left(20-22^{\circ} \mathrm{C}\right)$, equilibrated with $95 \% \mathrm{O}_{2}$ and $5 \% \mathrm{CO}_{2}$. After the mouse was killed by carbon dioxide inhalation, the muscle was removed and placed in a chamber perfused continuously with Ringer's solution. The tibialis anterior was used for all experiments in which miniature endplate currents (MEPCs) were recorded; however, in the tibialis anterior, damage of muscle fibers during dissection makes measurement of resting potential unreliable. Thus, for measurement of resting potential, the extensor digitorum longus was used rather than the tibialis anterior because it is much easier to dissect without damaging muscle fibers. Both muscles are composed primarily of fast fibers in mice (Agbulut et al., 2003; Pellegrino et al., 2003) and would thus be expected to respond similarly to manipulations of activity. Staining of muscle fibers and impalement were performed as described below. In $\mathrm{ClC}$ muscle, runs of action potentials (myotonia) sometimes occurred at the time of impalement. This damaged fibers and caused depolarization of the resting potential. Fibers in which myotonia occurred before the resting potential was recorded were discarded.

Measurement of MEPC amplitude. After dissection, the tibialis anterior muscle was partially bisected and folded apart to flatten the muscle. After pinning, muscle strips were stained with $10 \mu \mathrm{M}$ 4-(4-diethylaminostyryl)- $N$-methylpyridinium iodide (4-Di-2ASP) (Magrassi et al., 1987) and imaged with an upright epifluorescence microscope (Leica DMR). At this concentration, 4-Di-2ASP staining enabled visualization of surface nerve terminals as well as individual surface muscle fibers. All endplates were imaged and impaled within $100 \mu \mathrm{m}$, as described previously (Rich et al., 2002a). We used two-electrode voltage clamp to measure MEPC amplitude, as described previously (Rich et al., 2002a).

In $\mathrm{ClC}$ mice, changes occur in specific membrane resistance of muscle that might affect amplitude of the miniature endplate potential (MEPP); however, these changes should not affect the amplitude of MEPCs, which are measured using voltage clamp. We confirmed that loss of chloride conductance attributable to $\mathrm{ClC}-1$ chloride channels had no effect on MEPC amplitude using anthracene-9-carboxylic acid (9 AC) (100 $\mu \mathrm{M})$ to block ClC-1 channels in control muscle (Palade and Barchi, 1977). We recorded both the muscle membrane time constant as an indicator of muscle specific membrane resistance and the average MEPC amplitude in individual muscle fibers before and after block of ClC-1 chloride channels in four different control muscles (total $=24$ fibers before and after 9 $\mathrm{AC})$. Application of $9 \mathrm{AC}$ increased the average muscle membrane time constant by $70 \%$ (from 2.4 to $4.1 \mathrm{msec} ; p<0.01$ ). Despite the increase in muscle-specific membrane resistance, there was no effect on MEPC amplitude (1.27 nA before vs $1.15 \mathrm{nA}$ after; $p>0.05$ ).

In most experiments, muscle fibers were crushed away from the endplate band and voltage clamped to $-45 \mathrm{mV}$ to avoid movement after nerve stimulation (Barstad and Lilleheil, 1968; Glavinovic, 1979; Argentieri et al., 1992). All data on quantal content and endplate currents from nerve stimulation will be presented in other studies; however, in experiments in which acetylcholinesterase was blocked (using $1 \mu \mathrm{M}$ neostigmine), nerve stimulation was not performed so muscle fibers were clamped at $-70 \mathrm{mV}$ before and after application of neostigmine. This allowed these experiments to be performed without crushing muscle fibers.

Initial identification and alignment of MEPCs was performed using custom software (M. Pinter, Emory University, Atlanta, GA) as described previously (Rich et al., 2002b). For each endplate, a 1 min record of the membrane current was recorded. Most endplates had between 40 and 120 MEPCs in a 1 min span. Cumulative MEPC amplitude histograms were generated by sorting MEPC events from each endplate into 30 equal-sized bins from smallest to largest and calculating the average MEPC amplitude for each bin. The MEPC histograms of individual endplates were then averaged to generate a plot for each treatment group. In control and tetrodotoxin (TTX)-blocked groups, very few endplates had $<30$ MEPCs per minute; however, in TTX-blocked ClC endplates, a number of recordings had to be discarded. We analyzed the effect of discarding recordings with $<30$ MEPCs per minute on the average MEPC amplitude in TTX-blocked $\mathrm{ClC}$ endplates and found no consistent effect. It should be noted that MEPC amplitudes reported in Table 1 are from averages of animal averages, whereas cumulative plots were generated from individual endplates. Furthermore, the animal averages include endplates with $<30$ MEPCs per minute. The difference in measures did lead to some small discrepancies between Table 1 and the cumulative plots. For example, the average MEPC amplitude reported in Table 1 for TTX-blocked ClC endplates is slightly larger than that for TTX-blocked control endplates, whereas in Figure 6 it appears that MEPCs are slightly larger in TTX-blocked control endplates.

Denervation and TTX cuff application. Denervation of leg muscles was performed by removing a $5 \mathrm{~mm}$ segment of the left sciatic nerve in the upper thigh under intraperitoneal anesthesia $(140 \mathrm{mg} / \mathrm{kg}$ ketamine and $15 \mathrm{mg} / \mathrm{kg}$ zylaxine). TTX cuffs were fashioned from SILASTIC tubing and connected to Alzet osmotic pump model 1002 (Durect, Cupertino, CA) containing $850 \mu \mathrm{M}$ TTX dissolved in $0.9 \% \mathrm{NaCl}$ containing 200 $\mathrm{U} / \mathrm{ml}$ penicillin and $200 \mathrm{U} / \mathrm{ml}$ streptomycin. The tubing to the pump was filled with saline so that after surgery the foot muscles were not paralyzed. This allowed us to confirm that the nerve had not been injured during surgery. The next morning the mouse was checked for loss of ability to spread its toes to confirm that nerve block had developed. Before the mouse was killed at 8-9 d, the nerve block was checked again. Mice were killed using $\mathrm{CO}_{2}$ inhalation, and the tibialis anterior muscle was removed. We chose $8-9 \mathrm{~d}$ as the time point to study quantal content because at that time nerve damage by the TTX cuff with subsequent reinnervation could not confound results. In pilot experiments we found that after sciatic nerve crush at the point where we normally place the TTX cuff, reinnervation of muscle begins at $10 \mathrm{~d}$.

Quantitative immunofluorescence. To estimate AChR density at endplates, we first obtained single-plane confocal images (LSM510 Meta confocal system, Zeiss, Thornwood, NY) of endplates stained with saturating levels of fluorescein-labeled $\alpha$-bungarotoxin (BTX) (Molecular Probes, Eugene, OR). Separate images were taken at four different illuminating intensities by varying the laser intensity. This was done so that the slope of the increase of pixel intensity versus the increase in light intensity could be obtained as an indicator of fluorescence intensity and effects of varying black level could be avoided. Detector gain was maximized so that the lowest level of illumination could be used to avoid bleaching. Intensity of illumination ranged from 0.3 to $0.5 \%$ of maximum laser power. The average pixel intensity of two identical areas at the level of the postsynaptic primary gutter was then measured for each of the illumination intensities. This provided a plot of average pixel intensity versus illumination intensity. The slopes of these plots were then compared between endplates to assess relative AChR density.

To verify that this technique provided an accurate measure of the relative density of labeled AChRs, separate sections from single muscles were stained with two mixtures of BTX. In one mix, only fluoresceinconjugated BTX was used. The BTX was applied in a saturating dose so that all AChRs were labeled. In the second mix, 33\% of the BTX was labeled with rhodamine, whereas the remaining $67 \%$ was labeled with fluorescein. The slopes of pixel intensity versus illumination intensity for fluorescein-BTX labeling were compared for the two sets of endplates. We found that the average slope from endplates labeled with $67 \%$ fluorescein-BTX was $66 \pm 4 \%$ of the slope from endplates labeled with $100 \%$ fluorescein-BTX ( $n=4$ muscles; $p<0.01$ ). Our ability to detect a $33 \%$ change in AChR density to within $1 \%$ suggests that our technique is sufficiently sensitive to detect small increases in AChR density.

ClC mice. $\mathrm{ClCn} 1^{\text {adr-mto2J }}$ mice were obtained from The Jackson Laboratory (Bar Harbor, ME), and a breeding colony was established. Mice homozygous for the $\mathrm{ClC}$ mutation were identified by inability to rapidly right themselves after being turned on their backs at 2 weeks of age. Unaffected littermates, consisting of both mice that were heterozygous for the $\mathrm{ClC}$ mutation and mice that carried no copy of the mutation, were used as controls. Because no control mice had any myotonia during electromyography (EMG) recording from skeletal muscles, it appeared that heterozygous mice were completely asymptomatic.

Application of acetylcholine to endplates. Endplates that were on the surface of muscle fibers were selected for application of acetylcholine using the imaging technique outlined above. After MEPCs were acquired, a third electrode was advanced to within $50 \mu \mathrm{m}$ of the endplate, and $1 \mathrm{~mm}$ acetylcholine was applied using a $100 \mathrm{msec}$ pressure pulse at 20-30 psi (General Valve, Fairfield, NJ). Pipette tip diameter was be- 
tween 1 and $2 \mu \mathrm{m}$. Sulforhodamine 101 (10 $\mu \mathrm{m} / \mathrm{ml}$; Molecular Probes) was added to the acetylcholine solution to allow visualization of the puff of acetylcholine so that the electrode could be optimally positioned. Desensitization of the AChRs was prevented by rapid perfusion of Ringer's solution through the recording chamber and by maintaining a distance of $>20 \mu \mathrm{m}$ between the puffing electrode and the endplate. Using this protocol we could puff acetylcholine on individual endplates every $30 \mathrm{sec}$ without loss of amplitude attributable to desensitization. To measure extrajunctional acetylcholine sensitivity, the muscle was reimpaled 50$200 \mu \mathrm{m}$ from the endplate, and acetylcholine was applied to the extrajunctional region between the impaling electrodes. In recordings from control endplates, no detectable current was activated by ACh application at this distance. These data suggest that moving the application of ACh $50-200 \mu \mathrm{m}$ from the endplate was sufficient to prevent activation of junctional acetylcholine receptors.

Measurement of locomotor and EMG activity. Home cage activity monitoring was performed using a Noldus Ethovision 3.0 Automated Behavioral Tracking System (Leesburg, VA) to monitor animal movement. A digital camera was mounted $1 \mathrm{~m}$ above the animal's home cage. For recording purposes, the lid of the cage was removed, and the animal's movement was recorded as a digital file through the Noldus system and on VHS tape. Ethovision digitally stored and analyzed the position of the animal at a rate of 6 frames per second for $30 \mathrm{~min}$. Parameters chosen for analysis were total distance moved (centimeters) and movement (percentage of time moving). In addition, rearing frequency was scored manually for each animal.

EMG was performed using two subdermal electrodes placed over the tibialis anterior of mice that were anesthetized with inhaled Metofane. Wires attached to the electrodes were run over the skin to a point on the back using Super Glue. The mouse was then allowed to wake up, and EMG recording began after the effects of anesthetic had worn off. The EMG signal was amplified using a WPI (World Precision Instruments, Sarasota, FL) Iso-DAM8A amplifier. Gain was $10^{4}$; high filter was set at $10 \mathrm{kHz}$; low filter was set at $10 \mathrm{~Hz}$. The signal was recorded and digitized at $11 \mathrm{kHz}$ using Spike 2 software (Cambridge Electronic Design). Activity was measured for $20 \mathrm{~min}$ as the mouse moved about the cage. EMG activity was analyzed with Spike 2 software. Correlation with gait was made by continually observing behavior and marking when the mouse was stepping or rearing. After the recording was complete, the mouse was killed using $\mathrm{CO}_{2}$ inhalation. No effort was made to quantitate the relative firing rate of the presynaptic nerve terminal and muscle fibers in $\mathrm{ClC}$ mice for two reasons. First, although myotonic runs of action potentials could easily be heard during recordings from $\mathrm{ClC}$ mice, it was often difficult to distinguish the runs from simultaneous firing of motor units during analysis. Second, myotonic runs represent the firing of individual muscle fibers, whereas motor units are made up of many muscle fibers. Thus, to compare the frequency of myotonic runs with the frequency of motor unit firing will lead to overestimation of the increase in muscle relative to nerve activity.

Statistics. Data were tested for phenotype-related differences (i.e., $\mathrm{ClC}$ vs control) using nested ANOVA (Neter et al., 1990). In some experiments (cholinesterase blockade and acetylcholine puffing), nested analysis could not be performed because too few samples were obtained from individual animals. In these cases, data were pooled across experiments and compared using $t$ tests. Bonferroni correction was applied in all instances in which multiple comparisons were made between treatment groups. Mean values are shown \pm 1 SEM.

\section{Results}

\section{Quantal size is increased after block of activity because of a presynaptic mechanism}

Previous studies have shown that after blockade of synaptic activity, amplitude of MEPPs increases at the NMJ (Lomo and Rosenthal, 1972; Gundersen, 1990). It was suggested in both studies that the increase in MEPP amplitude was caused by muscle fiber atrophy and an increase in input resistance and thus did not represent a true increase in quantal size (amplitude of the MEPC). To determine quantal size after block of synaptic activ-
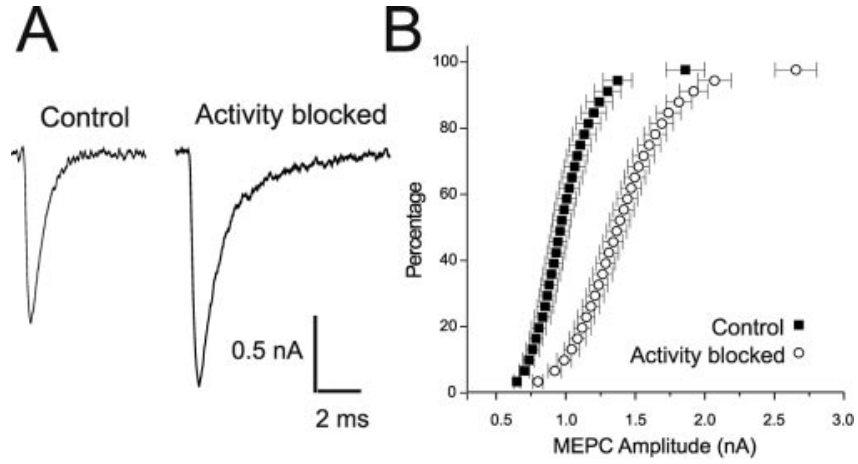

Figure 1. MEPC amplitude is increased after block of synaptic activity. $A$, Shown are representative average MEPC waveforms from a control endplate and an endplate after block of synaptic activity. Each trace represents the average of $>30$ MEPCs from the fiber. The MEPC from the endplate in which synaptic activity was blocked is 35\% larger. B, Cumulative distribution of MEPC amplitudes from control endplates and endplates in which synaptic activity was blocked ( $n=85$ endplates for control; $n=66$ after block of synaptic activity). Error bars represent SEM.

ity, we used voltage clamp (which is unaffected by input resistance) to measure MEPC amplitude after placement of a TTX cuff around the sciatic nerve for 8-10 d. After block of synaptic activity, MEPC amplitude increased by $40 \%$ (Fig. 1, Table 1) $(p<0.01)$. Placement of cuffs containing saline did not affect MEPC amplitude in three normal animals (1.25 $\pm 0.05 \mathrm{nA}$ in saline cuff leg vs $1.19 \pm 0.07 \mathrm{nA}$ in contralateral leg; $p>0.05)$. Thus block of synaptic activity causes an increase in quantal size at the mammalian NMJ in vivo.

Mechanisms that might underlie increased quantal size after block of activity include reduction in AChE activity, increased postsynaptic sensitivity to acetylcholine, or an increase in acetylcholine release from synaptic vesicles. We blocked AChE activity to determine whether we could eliminate differences in quantal size between control and TTX-blocked endplates. Blocking AChE activity with neostigmine caused a $250-350 \%$ prolongation of MEPC time constant, as reported previously (Katz and Miledi, 1973; Pennefather and Quastel, 1981; Glavinovic, 1986), but only a 15-50\% increase in MEPC amplitude in control endplates (Fig. $2 A)$. Differences in MEPC amplitude persisted after block of AChE (Fig. $2 B$, Table 2) $(p<0.01)$. The pattern of changes in MEPC amplitude and time constant after block of cholinesterase was very different from the pattern of changes found after block of synaptic activity. Thus, decreased cholinesterase activity is not a major contributor to increased quantal size after block of activity.

We next examined whether an increase in the number of AChRs might underlie increased quantal size. We compared AChR density between control and TTX-blocked endplates using quantitative immunofluorescence. Endplates were stained with a saturating dose of fluorescein conjugated $\alpha$-bungarotoxin and imaged with confocal microscopy (Fig. 3A) (see Materials and Methods). No increase in AChR density was found after block of synaptic activity (Fig. $3 B$ ). Our technique of quantitative immunofluorescence was able to detect a $33 \%$ reduction of AChR staining (attributable to varied mixtures of labeled $\alpha$-bungarotoxin; see Materials and Methods) to within 1\%. Thus, increased AChR density appears to play no role in the increase in quantal size.

Despite the absence of an increase in the number of AChRs, it is possible that a change in AChR subunit composition might contribute to an increase in quantal size. The $\gamma$ subunit of the AChR is upregulated after loss of muscle activity (Witzemann et 
Table 1. MEPC amplitude after manipulations of activity

\begin{tabular}{llll}
\hline & Control & Control TTX & CIC \\
\hline MEPC (nA) & $1.04 \pm 0.03$ & $1.46 \pm 0.09^{* *}$ & $1.54 \pm 0.07^{* *}$ \\
Time to peak of MEPC (msec) & $0.48 \pm 0.02$ & $0.55 \pm 0.02^{*}$ & $0.51 \pm 0.02$ \\
MEPC time constant (msec) & $1.30 \pm 0.04$ & $1.43 \pm 0.07$ & $1.60 \pm 0.07^{* *}$ \\
Number of animals & 11 & 7 & $0.05 \pm 0.02^{*}$ \\
\hline
\end{tabular}

Differences from control at the 0.01 level by nested ANOVA are indicated by double asterisks, and differences at the 0.05 level are indicated by a single asterisk. All data represent the animal averages \pm SEM.

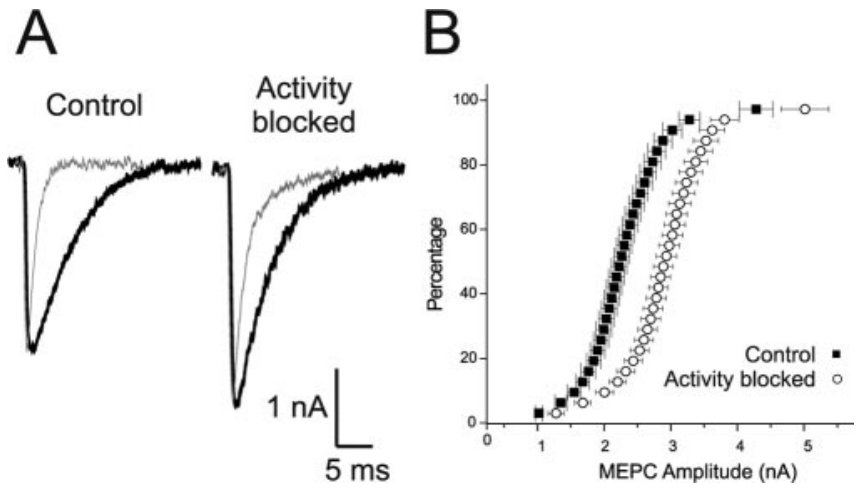

Figure 2. Decreased activity of acetylcholinesterase is not the primary cause of increased MEPC amplitude. $A$, Shown in black are average MEPC waveforms from endplates after blockade of cholinesterase activity by neostigmine. Superimposed on the traces in gray are the normalized MEPC traces from Figure 1 representing MEPCs in endplates in which AChE is active. The increase in MEPC amplitude after block of activity persists after block of AChE. Block of AChE caused prolongation of the time to peak and a marked prolongation of the time constant of MEPCs. $B$, Cumulative distribution of MEPC amplitudes from control and TTX-blocked endplates after blockade of AChE activity by neostigmine ( $n=30$ endplates for control; $n=20$ after block of synaptic activity). The holding potential was $-70 \mathrm{mV}$ for this set of experiments rather than $-45 \mathrm{mV}$ as in Figure 1. Error bars represent SEM.

al., 1991), and AChRs containing the $\gamma$ subunit, although having a lower single-channel conductance, have a much longer mean open time (6 vs $1 \mathrm{msec}$ ) (Schuetze and Role, 1987). If increased quantal size were related to expression of the $\gamma$ subunit and longer AChR open times, increases in MEPC amplitude would be accompanied by increases in the MEPC decay time constant and MEPC half-width; however, there was no significant increase in either MEPC time constant (Table 1$)(p=0.11)$ or MEPC halfwidth $[1.36 \pm 0.04$ (control) vs $1.43 \pm 0.07$ (TTX-blocked); $p=$ 0.42] after block of activity. The absence of increases in time constant and half-width suggests that most AChRs at endplates after block of activity do not contain the $\gamma$ subunit. Although we cannot rule out an increase in single-channel AChR conductance that is not accompanied by an increase in open time, it appears likely that the mechanism underlying increased quantal size after block of activity is presynaptic and involves increased release of acetylcholine.

\section{Characterization of $\mathrm{ClC}$ mice}

We wished to determine whether the trigger for increased quantal size after block of synaptic activity involved loss of postsynaptic activity. To examine this we used mice that have a null mutation in the muscle-specific chloride channel ClC-1 (Klocke et al., 1994). The increase in specific membrane resistance caused by loss of chloride channel function causes spontaneous activity of skeletal muscle (Steinmeyer et al., 1991b; Gronemeier et al., 1994). It has been shown that the frequency of spontaneous muscle action potentials in $\mathrm{ClC}$ mice is sufficient to prevent denervation-induced changes in expression of myogenin, MyoD and the acetylcholine receptor $\alpha$ subunit (Klocke et al., 1994).
We further characterized the properties of $\mathrm{ClC}$ mice so that these could be related to possible changes in quantal size. In $\mathrm{ClC}$ mice, spontaneous runs of muscle action potentials occur in the absence of nerve action potentials (Fig. $4 A$ ). We confirmed that spontaneous activity of $\mathrm{ClC}$ muscle was sufficient to prevent the upregulation of extrajunctional AChRs that normally occurs 1 week after block of nerve activity (Lomo and Rosenthal, 1972; Lomo and Westgaard, 1975) ( $n=9$ fibers) (Fig. $4 B$ ). Spontaneous muscle activity in $\mathrm{ClC}$ mice was also sufficient to prevent the depolarization of muscle fiber resting potential normally observed after 1 week of denervation (McArdle, 1983) (Fig. 4C). Together, these results suggest that spontaneous muscle activity in $\mathrm{ClC}$ mice is sufficient to prevent a number of distinct denervation-induced changes in skeletal muscle.

\section{Quantal size is increased in $\mathrm{ClC}$ mice because of a presynaptic mechanism}

We examined whether quantal size was altered in $\mathrm{ClC}$ mice with intact presynaptic activity and found that MEPC amplitude was increased by $48 \%$ relative to control (Fig. 5 A, Table 1$)(p<0.01)$. One possible cause of this increase is an effect attributable to loss of $\mathrm{ClC}-1$ function; however, the $\mathrm{ClC}-1$ gene is not expressed in the nervous system (Steinmeyer et al., 1991a), so changes in function of the NMJ are unlikely to be caused by loss of chloride conductance in neurons. Furthermore, block of chloride conductance in neurons decreases rather than increases quantal size (Pothos et al., 2002; Van der Kloot, 2003). Developmental changes attributable to loss of $\mathrm{ClC}$ function seem an unlikely explanation for the increase in quantal size, because $\mathrm{ClC}-1$ expression is upregulated in skeletal muscle after the first week of life (Conte Camerino et al., 1989; Wischmeyer et al., 1993), when development of the NMJ is essentially complete (Sanes and Lichtman, 1999).

As mentioned above, other mechanisms that might underlie increased quantal size include reduction in AChE activity, increased postsynaptic sensitivity to acetylcholine, or an increase in acetylcholine release from synaptic vesicles. After block of AChE, differences in MEPC amplitude between control and $\mathrm{ClC}$ endplates persisted (Fig. $5 B$, Table 2) $(p<0.01$ ). Thus, decreased AChE activity is not a major contributor to the increase in MEPC amplitude in $\mathrm{ClC}$ endplates. To determine whether postsynaptic sensitivity to acetylcholine was increased we applied acetylcholine. Interpretation of application of acetylcholine can be complicated by the presence of extrajunctional AChRs, so we confirmed that in both $\mathrm{ClC}$ and control muscle fibers we obtained responses to applied acetylcholine only at the endplate (Fig. 4B). We measured both the MEPC amplitude and the response to applied acetylcholine at individual control and $\mathrm{ClC}$ endplates. Despite a $40 \%$ increase in MEPC amplitude in this group of $\mathrm{ClC}$ endplates $(p<0.01)$ relative to control, there was no statistically significant difference in the response to applied acetylcholine (Fig. 5C). We also compared AChR density between control and $\mathrm{ClC}$ endplates using quantitative immunofluorescence. $\mathrm{ClC}$ endplates had a modest $(20 \%)$ but statistically significant reduction 
Table 2. Loss of cholinesterase activity is not the cause of increased MEPC amplitude

\begin{tabular}{|c|c|c|c|c|c|c|}
\hline & \multicolumn{3}{|c|}{ Cholinesterase active } & \multicolumn{3}{|c|}{ Cholinesterase blocked } \\
\hline & Amplitude & Time to peak & Time constant & Amplitude & Time to peak & Time constant \\
\hline Control & $1.41 \pm 0.08$ & $0.51 \pm 0.01$ & $1.88 \pm 0.05$ & $2.11 \pm 0.11$ & $0.77 \pm 0.04$ & $5.08 \pm 0.13$ \\
\hline Control TTX & $2.41 \pm 0.10^{*}$ & $0.52 \pm 0.02$ & $2.07 \pm 0.10$ & $2.77 \pm 0.13^{*}$ & $0.69 \pm 0.03$ & $4.95 \pm 0.06$ \\
\hline $\mathrm{ClC}$ & $2.46 \pm 0.08^{*}$ & $0.58 \pm 0.01$ & $1.67 \pm 0.05$ & $3.27 \pm 0.10^{*}$ & $0.78 \pm 0.03$ & $5.28 \pm 0.12$ \\
\hline CIC TTX & $2.62 \pm 0.09^{*}$ & $0.52 \pm 0.02$ & $1.61 \pm 0.08$ & $3.03 \pm 0.10^{*}$ & $0.94 \pm 0.05$ & $5.64 \pm 0.19$ \\
\hline
\end{tabular}

Number of endplates (control; cholinesterase active, 30; cholinesterase blocked, 30; control TTX, 20 and 20, respectively; CIC, 40 and 60; (IC TTX, 29 and 50). . ${ }^{p}<0.01$ versus control; Student's $t$ test. MEPC amplitude is larger in this set 0 . experiments than in the data presented in Table 1 because muscle fibers were voltage clamped to -70 rather than $-45 \mathrm{mV}$.

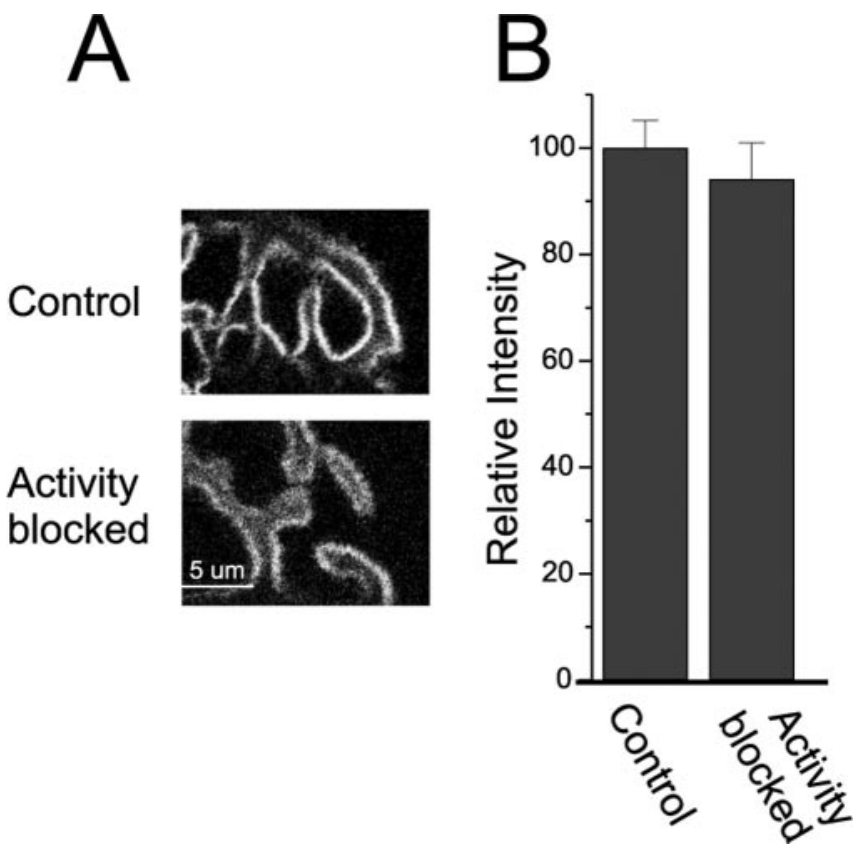

Figure 3. Quantitative immunofluorescence reveals no increase in AChR density after block of synaptic activity. $A$, Shown are individual confocal sections used to quantitate AChR density through a control endplate and an endplate in which synaptic activity was blocked. $B$, The relative AChR labeling in control endplates is plotted relative to TTX-blocked control endplates. There is no significant difference in labeling of control endplates versus TTX-blocked endplates ( $n=37$ endplates from 4 muscles for control; $n=38$ endplates from 4 muscles after block of synaptic activity).

in staining intensity relative to control endplates $(p<0.01)$ (Fig. $5 D)$. These data suggest that, if anything, AChR density is lower in $\mathrm{ClC}$ endplates despite the increase in quantal size. Together with functional data from application of $\mathrm{ACh}$, these data suggest that increased sensitivity of the postsynaptic cell to acetylcholine plays no role in increased quantal size at $\mathrm{ClC}$ endplates. By elimination, it appears likely that the mechanism underlying increased MEPC amplitude in $\mathrm{ClC}$ mice is presynaptic and involves increased release of acetylcholine.

\section{Presynaptic activity is decreased in $\mathrm{ClC}$ mice}

Initial observations indicated a dramatic reduction of movement of $\mathrm{ClC}$ mutant mice compared with their wild-type littermates. This may be caused by discomfort associated with movementinduced muscle myotonia. Reduced locomotor activity is likely to correlate with reduced motor neuron firing (and thus presynaptic terminal firing). Because reduction of synaptic activity in control mice triggers an increase in quantal size, we further examined the reduction of behavioral activity in $\mathrm{ClC}$ mice. We compared locomotor activity between $\mathrm{ClC}$ mutants and unaffected littermates by monitoring home cage activity (Tillerson et al., 2002). Using an automated tracking system, mice were observed in their home cages for a period of $30 \mathrm{~min}$. Total activity, percentage of time moving, and rearing were all reduced by $\sim 75 \%$ in $\mathrm{ClC}$ mice compared with their wild-type littermate controls (Table 3). Other measures of locomotor activity, including open field test and the grid performance test, yielded similar reductions (data not shown).

To determine whether behavioral measures of activity correlated with motor unit activity, we measured 20 min of EMG activity with subdermal electrodes placed over the tibialis anterior muscle of two awake, behaving control mice and two awake, behaving $\mathrm{ClC}$ mice. In both control and $\mathrm{ClC}$ mice, motor units in the tibialis anterior were activated only during stepping and rearing. When the mice were at rest, there was no motor unit activity in the tibialis anterior muscle. Our findings agree with data indicating that tibialis anterior motor units in rodents are active only during movement (Roy et al., 1991). Thus, the 75\% reduction in behavioral measures of activity in $\mathrm{ClC}$ mice indicates that there is a $75 \%$ reduction in presynaptic action potentials in $\mathrm{ClC}$ motor units relative to control.

\section{Effects of nerve block on quantal size in $\mathrm{ClC}$ mice}

If increased quantal size in $\mathrm{ClC}$ mice is caused by a reduction of presynaptic action potentials, then experimental block of presynaptic action potentials in $\mathrm{ClC}$ mice (where presynaptic activity is already reduced by $75 \%$ ) should have less effect on quantal size than in control mice. Furthermore, after complete block of presynaptic activity, quantal size should be similar in control and $\mathrm{ClC}$ mice. To test these predictions, we blocked presynaptic activity by placing a TTX cuff around the sciatic nerve for $8-10 \mathrm{~d}$ in $\mathrm{ClC}$ mice. As predicted, MEPC amplitude at $\mathrm{ClC}$ endplates increased less than in controls (Table 1). Furthermore, MEPC amplitude was similar in TTX-blocked normal and ClC endplates (Fig. 6, Table 1) ( $p>0.05)$, despite the difference in levels of postsynaptic activity. Thus, we found no correlation between MEPC amplitude and the level of postsynaptic activity; however, there was a correlation between the level of presynaptic activity and quantal size. ClC, TTX-blocked ClC, and TTX-blocked normal endplates all have similarly increased quantal size $(p>0.05$ for all comparisons among these groups) and reduced presynaptic activity relative to untreated controls.

\section{Discussion}

We show here that quantal size is increased in vivo at the NMJ after block of synaptic activity. The mechanism underlying the increase in quantal size appears to be presynaptic and involves increased release of acetylcholine from vesicles. Studies of the trigger that induced the increase in quantal size were performed using control mice and mice in which postsynaptic excitability is increased because of loss of chloride conductance in skeletal muscle (ClC mice). Data from these studies suggest that reduction of presynaptic activity may be the trigger that signals an increase in quantal size. We propose that presynaptic activity modulates 
quantal size at the mammalian NMJ by regulating the amount of acetylcholine released from synaptic vesicles.

\section{Mechanisms underlying increased quantal size at the NMJ}

Three mechanisms might contribute to the increased quantal size in the current study: decreased AChE activity, increased sensitivity of the postsynaptic cell to acetylcholine, or increased release of acetylcholine from individual synaptic vesicles. We examined the role of reduced AChE activity in increased quantal size and found that complete block of AChE caused only modest increases in MEPC amplitude that were accompanied by large increases in MEPC decay time constant, which were not observed in either $\mathrm{ClC}$ or control mice after block of synaptic activity. Thus, reduction of AChE did not mimic changes in MEPCs that were found in endplates in which MEPC amplitude was increased. This suggests that loss of AChE activity is not the mechanism underlying increased quantal size in either control endplates in which synaptic activity was blocked or $\mathrm{ClC}$ endplates. We also examined the role of an increase in postsynaptic AChRs in causing increased quantal size by quantitative immunofluorescent measures of AChR density. Our data suggest that increases in AChRs cannot account for the increase in quantal size. In $\mathrm{ClC}$ mice we were also able to rule out an increase in postsynaptic acetylcholine sensitivity by application of acetylcholine. Although we cannot rule out an increase in single-channel conductance of AChRs as the cause of increased quantal size in TTX-blocked control endplates, it appears likely that increased acetylcholine release from individual vesicles is the principal mechanism underlying the various increases in quantal size observed in this study.

\section{Modulation of quantal size at the NMJ}

A central question in this study is what triggers the increase in quantal size at endplates of $\mathrm{ClC}$ mice before application of a TTX cuff to the nerve. Although we favor the possibility that increased quantal size in $\mathrm{ClC}$ endplates is secondary to a reduction of presynaptic activity, we cannot rule out an activity-independent change in quantal size. It is also possible that reduction of postsynaptic activity (i.e., number of muscle fiber action potentials) modulates quantal size; however, in a study in which postsynaptic activity was selectively decreased at the mammalian NMJ by blocking AChRs, quantal size did not increase (Berg and Hall, 1975). A similar result was obtained at the Drosophila NMJ after selective reduction of postsynaptic activity by overexpression of potassium channels (Paradis et al., 2001). It has also been shown at the Drosophila NMJ that naturally occurring differences in quantal size in two neurons innervating the same postsynaptic muscle fibers correlate with differences in the size of presynaptic vesicles as well as differences in presynaptic activity levels (Karunanithi et al., 2002). We found that in $\mathrm{ClC}$ and TTX-blocked $\mathrm{ClC}$ endplates, there is enough muscle activity to prevent activitydependent changes in muscle (such as an increase in AChR ex- pression), yet quantal size is increased. Our data, together with previously published data, suggest that postsynaptic action potentials play only a small role in the regulation of quantal size at the NMJ. The most parsimonious explanation for both our data and previously published data is that the reduction in presynaptic activity (the number of presynaptic action potentials) triggers increased quantal size.

\section{Do similar mechanisms regulate quantal size at neuromuscular and CNS synapses?}

An important question is whether regulation of quantal size at the mammalian NMJ differs from regulation of quantal size at CNS synapses. The role of presynaptic versus postsynaptic activity in triggering changes in quantal size is not clear at CNS synapses because most studies have not examined the distinct roles of presynaptic versus postsynaptic activity. In the only study that we are aware of in which postsynaptic activity was selectively reduced at neuronal synapses, quantal size remained unchanged (Burrone et al., 2002). This finding raises the possibility that postsynaptic activity plays only a small role in the regulation of quantal size at CNS synapses. It may be that previous results in which quantal size increased after reduction of synaptic activity were the consequence of a reduction in presynaptic rather than postsynaptic activity (O'Brien et al., 1998; Turrigiano et al., 1998; Burrone et al., 2002; Desai et al., 2002). Thus, there is no evidence suggesting that presynaptic and postsynaptic activities have different roles in modulation of quantal size at the NMJ and synapses between neurons. 


\section{A}

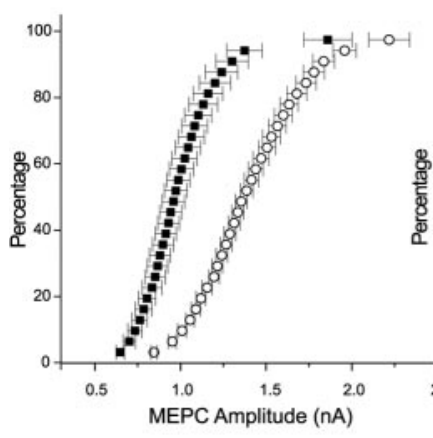

$$
\text { C }
$$

MEPC amplitude
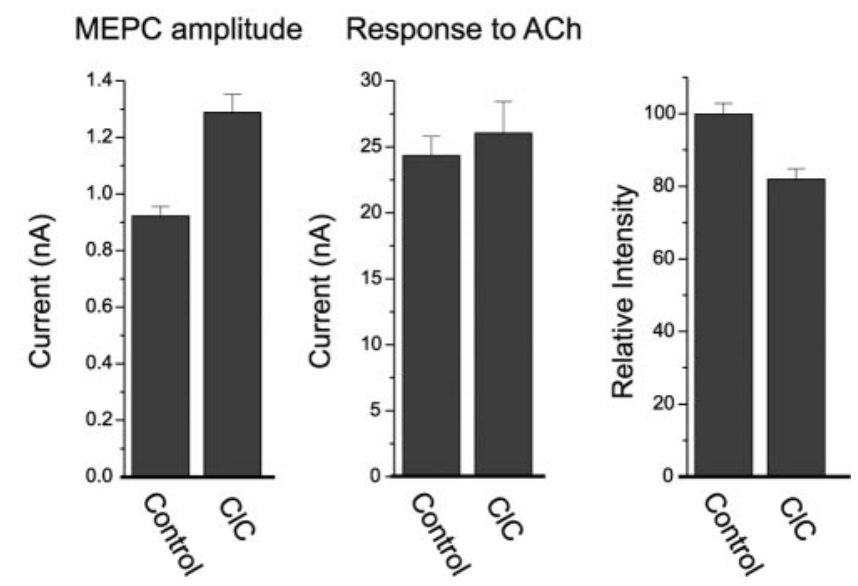

Figure 5. MEPC amplitude is increased at $\mathrm{CIC}$ endplates because of a presynaptic mechanism. $A$, Cumulative distribution of MEPC amplitudes from CIC endplates $(n=99)$ relative to the control plot from Figure $1 C$. Holding potential was $-45 \mathrm{mV}$. B, Cumulative distribution of MEPC amplitudes after block of AChE from $\mathrm{CIC}$ endplates $(n=60)$ relative to the control plot from Figure $2 B$. The difference in MEPC amplitude persists after block of AChE. Holding potential was $-70 \mathrm{mV}$. C, Shown are bar graphs of MEPC amplitude and the amplitude of the response to applied acetylcholine in 21 control and 24 CIC endplates. Despite a 40\% increase in MEPC amplitude in CIC relative to control $(p<0.01)$, there was no statistically significant difference in the response to applied acetylcholine. D, Quantitative immunofluorescence reveals no increase in AChR density in CIC endplates. The relative AChR labeling in CIC endplates is plotted relative to control endplates. There is a $20 \%$ reduction in $\mathrm{AChR}$ intensity in $\mathrm{CIC}$ endplates relative to control ( $p<0.01 ; n=38$ endplates from 4 muscles for control; $n=32$ endplates from 4 muscles for $(\mathrm{IC})$.

Table 3. Locomotor activity is decreased in $\mathrm{CIC}$ mice

\begin{tabular}{llll}
\hline & $\begin{array}{l}\text { Average distance } \\
\text { moved }(\mathrm{cm})\end{array}$ & $\begin{array}{l}\text { Percentage of } \\
\text { time moving }\end{array}$ & $\begin{array}{l}\text { Rearing } \\
\text { frequency }\end{array}$ \\
\hline Control $(n=8)$ & $5983 \pm 364$ & $65 \pm 3$ & $247 \pm 19$ \\
CIC $(n=6)$ & $1242 \pm 233$ & $19 \pm 10$ & $41 \pm 15$ \\
CIC/control activity & $21 \%$ & $29 \%$ & $17 \%$ \\
\hline
\end{tabular}

All data represent the average \pm SEM. $n=$ number of animals.

The mechanism underlying increased quantal size may differ in the two systems, and it is currently thought that a change in the number of postsynaptic neurotransmitter receptors (rather than increased neurotransmitter release) is the mechanism underlying the increase in quantal size at CNS synapses (Turrigiano and Nelson, 2004); however, data regarding the mechanism underlying increased quantal size at the NMJ and CNS synapses may be more similar than is evident at first glance. The idea that a postsynaptic mechanism (increased neurotransmitter number) underlies increased quantal size at synapses between neurons is

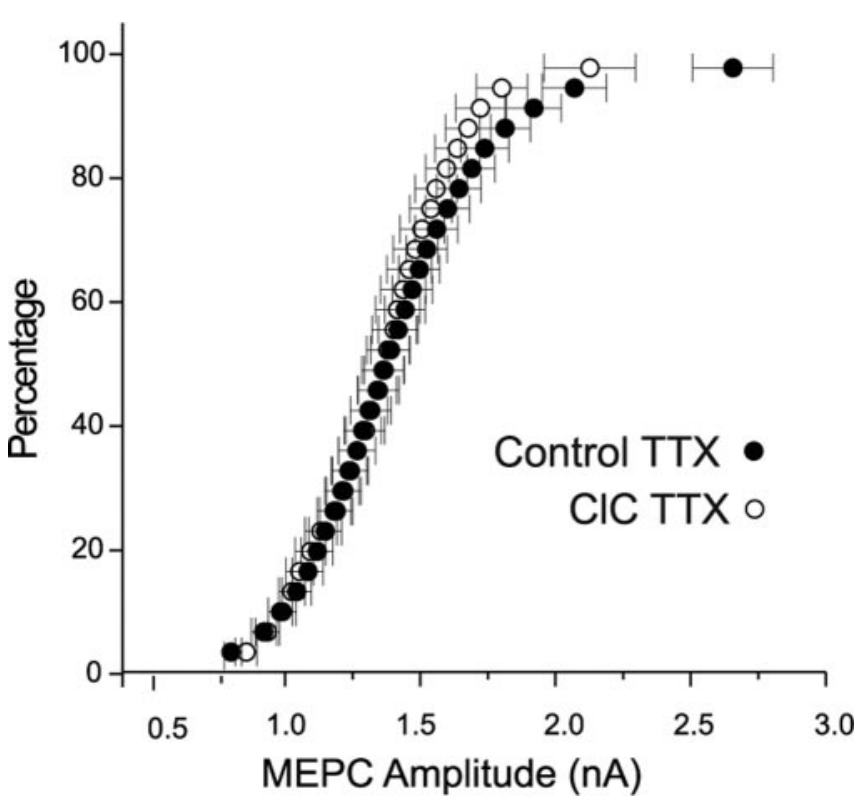

Figure 6. MEPC amplitude is similar in TTX-blocked control and TTX-blocked CIC endplates. Cumulative distribution of MEPC amplitudes from TTX-blocked control and TTX-blocked CIC endplates ( $n=38$ for CIC TTX; $n=66$ for TTX control). The holding potential was $-45 \mathrm{mV}$.

based in large part on application of neurotransmitter to synapses (O'Brien et al., 1998; Turrigiano et al., 1998; Watt et al., 2000). At the NMJ we found an increase in response to application of acetylcholine after block of activity at normal endplates (Fig. 4). Thus, the NMJ has the same increase in response to applied neurotransmitter after block of activity as is found at synapses between neurons; however, at the NMJ this increase appears to be caused by extrajunctional AChRs (Fig. 4) and is not accompanied by an increase in the density of synaptic AChRs as measured by quantitative immunofluorescence. At neuronal synapses it is very difficult to determine whether there is an increase in extrajunctional receptors.

Quantitative immunofluorescence at synapses between neurons has shown increased neurotransmitter receptor number after treatments that increased quantal size (O'Brien et al., 1998). We used quantitative immunofluorescence at the NMJ and reached the opposite conclusion. One explanation for the difference is that the mechanism underlying increased quantal size differs in the two systems. Another explanation for the difference is that different parameters were measured. We measured density of AChRs rather than total number in the synapse as done previously. When previous data (O'Brien et al., 1998) are converted into estimates of density of neurotransmitter receptors, changes become small and do not consistently parallel changes in quantal size (R. O’Brien, personal communication). Thus, data on receptor density are similar at the NMJ and CNS synapses. The primary difference between CNS synapses and the NMJ appears to be that synaptic size increases after block of activity at CNS synapses, whereas it remains unchanged at the NMJ. It remains unknown whether density of receptors or the size of the synapse correlates better with quantal size. Thus, it is unclear whether there is a difference in either the signal or mechanism underlying regulation of quantal size at neuromuscular and CNS synapses.

The proposal that quantal size is regulated by varying vesicle transmitter content is supported by a number of studies (Sulzer and Edwards, 2000; Atwood and Karunanithi, 2002; Liu, 2003). It has been demonstrated that variation in quantal size at GABAer- 
gic synapses is caused by variation in the transmitter content of synaptic vesicles (Frerking et al., 1995). Presynaptic control of quantal size has been observed after a number of manipulations in vitro (Van der Kloot, 1991; Sulzer and Pothos, 2000). Repetitive stimulation has been shown to alter the amount of neurotransmitter released by each quantum over short time periods (Elhamdani et al., 2001; Naves and Van der Kloot, 2001; Burgoyne and Barclay, 2002; Pothos et al., 2002), possibly because of changes in activity of vesicular transporters (Desnos et al., 1995). Thus, it seems reasonable to propose that activity-dependent regulation of quantal size may involve changes in presynaptic release of neurotransmitter from vesicles.

In summary, it remains unclear whether changes in presynaptic or postsynaptic activity trigger changes in quantal size and quantal content after changes in synaptic activity at CNS synapses. The site of expression of various activity-induced changes in synaptic function also remains unknown at CNS synapses. Our data from the NMJ in vivo suggest that both the trigger and site of expression for increases in quantal size may be presynaptic. Understanding the locus for both the trigger and site of expression of changes in synaptic function is a prerequisite to determining the molecular mechanisms underlying activity-dependent regulation of synaptic function.

\section{References}

Agbulut O, Noirez P, Beaumont F, Butler-Browne G (2003) Myosin heavy chain isoforms in postnatal muscle development of mice. Biol Cell 95:399-406.

Argentieri TM, Aiken SP, Laxminarayan S, McArdle JJ (1992) Characteristics of synaptic transmission in reinnervating rat skeletal muscle. Pflügers Arch Eur J Physiol 421:256-261.

Atwood HL, Karunanithi S (2002) Diversification of synaptic strength: presynaptic elements. Nat Rev Neurosci 3:497-516.

Barstad JA, Lilleheil G (1968) Transversally cut diaphragm preparation from rat. An adjuvant tool in the study of the physiology and pharmacology of the myoneural junction. Arch Int Pharmacodyn Ther 175:373-390.

Berg DK, Hall ZW (1975) Increased extrajunctional acetylcholine sensitivity produced by chronic post-synaptic neuromuscular blockade. J Physiol (Lond) 244:659-676.

Burgoyne RD, Barclay JW (2002) Splitting the quantum: regulation of quantal release during vesicle fusion. Trends Neurosci 25:176-178.

Burrone J, Murthy VN (2003) Synaptic gain control and homeostasis. Curr Opin Neurobiol 13:560-567.

Burrone J, O’Byrne M, Murthy VN (2002) Multiple forms of synaptic plasticity triggered by selective suppression of activity in individual neurons. Nature 420:414-418.

Conte Camerino D, De Luca A, Mambrini M, Vrbova G (1989) Membrane ionic conductances in normal and denervated skeletal muscle of the rat during development. Pflügers Arch Eur J Physiol 413:568-570.

Davis GW, Bezprozvanny I (2001) Maintaining the stability of neural function: a homeostatic hypothesis. Annu Rev Physiol 63:847-869.

Desai NS, Cudmore RH, Nelson SB, Turrigiano GG (2002) Critical periods for experience-dependent synaptic scaling in visual cortex. Nat Neurosci 5:783-789.

Desnos C, Laran MP, Langley K, Aunis D, Henry JP (1995) Long term stimulation changes the vesicular monoamine transporter content of chromaffin granules. J Biol Chem 270:16030-16038.

Elhamdani A, Palfrey HC, Artalejo CR (2001) Quantal size is dependent on stimulation frequency and calcium entry in calf chromaffin cells. Neuron 31:819-830.

Frerking M, Borges S, Wilson M (1995) Variation in GABA mini amplitude is the consequence of variation in transmitter concentration. Neuron 15:885-895.

Glavinovic MI (1979) Voltage clamping of unparalysed cut rat diaphragm for study of transmitter release. J Physiol (Lond) 290:467-480.

Glavinovic MI (1986) Variability of quantal events in control solution and after cholinesterase blockade in frog. Neuroscience 17:519-526.

Gronemeier M, Condie A, Prosser J, Steinmeyer K, Jentsch TJ, Jockusch H
(1994) Nonsense and missense mutations in the muscular chloride channel gene Clc-1 of myotonic mice. J Biol Chem 269:5963-5967.

Gundersen K (1990) Spontaneous activity at long-term silenced synapses in rat muscle. J Physiol (Lond) 430:399-418.

Karunanithi S, Marin L, Wong K, Atwood HL (2002) Quantal size and variation determined by vesicle size in normal and mutant Drosophila glutamatergic synapses. J Neurosci 22:10267-10276.

Katz B, Miledi R (1973) The binding of acetylcholine to receptors and its removal from the synaptic cleft. J Physiol (Lond) 231:549-574.

Klocke R, Steinmeyer K, Jentsch TJ, Jockusch H (1994) Role of innervation, excitability, and myogenic factors in the expression of the muscular chloride channel ClC-1. A study on normal and myotonic muscle. J Biol Chem 269:27635-27639.

Liu G (2003) Presynaptic control of quantal size: kinetic mechanisms and implications for synaptic transmission and plasticity. Curr Opin Neurobiol 13:324-331.

Lomo T, Rosenthal J (1972) Control of ACh sensitivity by muscle activity in the rat. J Physiol (Lond) 221:493-513.

Lomo T, Westgaard RH (1975) Further studies on the control of ACh sensitivity by muscle activity in the rat. J Physiol (Lond) 252:603-626.

Magrassi L, Purves D, Lichtman JW (1987) Fluorescent probes that stain living nerve terminals. J Neurosci 7:1207-1214.

McArdle JJ (1983) Molecular aspects of the trophic influence of nerve on muscle. Prog Neurobiol 21:135-198.

Naves LA, Van der Kloot W (2001) Repetitive nerve stimulation decreases the acetylcholine content of quanta at the frog neuromuscular junction. J Physiol (Lond) 532:637-647.

Neter J, Wasserman W, Kutner MH (1990) Applied linear statistical models, Ed 3. Boston: Irwin.

O’Brien RJ, Kamboj S, Ehlers MD, Rosen KR, Fischbach GD, Huganir RL (1998) Activity-dependent modulation of synaptic AMPA receptor accumulation. Neuron 21:1067-1078.

Palade PT, Barchi RL (1977) Characteristics of the chloride conductance in muscle fibers of the rat diaphragm. J Gen Physiol 69:325-342.

Paradis S, Sweeney ST, Davis GW (2001) Homeostatic control of presynaptic release is triggered by postsynaptic membrane depolarization. Neuron 30:737-749.

Pellegrino MA, Canepari M, Rossi R, D’Antona G, Reggiani C, Bottinelli R (2003) Orthologous myosin isoforms and scaling of shortening velocity with body size in mouse, rat, rabbit and human muscles. J Physiol (Lond) 546:677-689.

Pennefather P, Quastel DM (1981) Relation between subsynaptic receptor blockade and response to quantal transmitter at the mouse neuromuscular junction. J Gen Physiol 78:313-344.

Pothos EN, Mosharov E, Liu KP, Setlik W, Haburcak M, Baldini G, Gershon MD, Tamir H, Sulzer D (2002) Stimulation-dependent regulation of the $\mathrm{pH}$, volume and quantal size of bovine and rodent secretory vesicles. J Physiol (Lond) 542:453-476.

Rich MM, Waldeck RF, Cork LC, Balice-Gordon RJ, Fyffe RE, Wang X, Cope TC, Pinter MJ (2002a) Reduced endplate currents underlie motor unit dysfunction in canine motor neuron disease. J Neurophysiol 88:3293-3304.

Rich MM, Wang X, Cope TC, Pinter MJ (2002b) Reduced neuromuscular quantal content with normal synaptic release time course and depression in canine motor neuron disease. J Neurophysiol 88:3305-3314.

Roy RR, Hutchison DL, Pierotti DJ, Hodgson JA, Edgerton VR (1991) EMG patterns of rat ankle extensors and flexors during treadmill locomotion and swimming. J Appl Physiol 70:2522-2529.

Sanes JR, Lichtman JW (1999) Development of the vertebrate neuromuscular junction. Annu Rev Neurosci 22:389-442.

Schuetze SM, Role LW (1987) Developmental regulation of nicotinic acetylcholine receptors. Annu Rev Neurosci 10:403-457.

Steinmeyer K, Ortland C, Jentsch TJ (1991a) Primary structure and functional expression of a developmentally regulated skeletal muscle chloride channel. Nature 354:301-304.

Steinmeyer K, Klocke R, Ortland C, Gronemeier M, Jockusch H, Grunder S, Jentsch TJ (1991b) Inactivation of muscle chloride channel by transposon insertion in myotonic mice. Nature 354:304-308.

Sulzer D, Edwards R (2000) Vesicles: equal in neurotransmitter concentration but not in volume. Neuron 28:5-7.

Sulzer D, Pothos EN (2000) Regulation of quantal size by presynaptic mechanisms. Rev Neurosci 11:159-212. 
Tillerson JL, Caudle WM, Reveron ME, Miller GW (2002) Detection of behavioral impairments correlated to neurochemical deficits in mice treated with moderate doses of 1-methyl-4-phenyl-1,2,3,6-tetrahydropyridine. Exp Neurol 178:80-90.

Turrigiano GG, Nelson SB (2004) Homeostatic plasticity in the developing nervous system. Nat Rev Neurosci 5:97-107.

Turrigiano GG, Leslie KR, Desai NS, Rutherford LC, Nelson SB (1998) Activity-dependent scaling of quantal amplitude in neocortical neurons. Nature 391:892-896.

Van der Kloot W (1991) The regulation of quantal size. Prog Neurobiol 36:93-130.

Van der Kloot W (2003) A chloride channel blocker reduces acetylcholine uptake into synaptic vesicles at the frog neuromuscular junction. Brain Res 961:287-289.

Watt AJ, van Rossum MC, MacLeod KM, Nelson SB, Turrigiano GG (2000) Activity coregulates quantal AMPA and NMDA currents at neocortical synapses. Neuron 26:659-670.

Wischmeyer E, Nolte E, Klocke R, Jockusch H, Brinkmeier H (1993) Development of electrical myotonia in the ADR mouse: role of chloride conductance in myotubes and neonatal animals. Neuromuscul Disord 3:267-274.

Witzemann V, Brenner HR, Sakmann B (1991) Neural factors regulate AChR subunit mRNAs at rat neuromuscular synapses. J Cell Biol 114: 125-141. 